\section{Embed stormwater use in city planning}

Potable water resources are being depleted at an alarming rate worldwide. Storm water is a hugely under-utilized resource that could help as extreme weather events become more frequent.

The challenges of collecting and using storm water mean that the practice is not widespread. Rainfall tends to be seasonal, so storm water must be stored for use in dry periods in natural underground aquifers (see A. Mankad et al. J. Clean. Prod. $\mathbf{8 9}, 214-223 ; 2015$ ) or in specially built reservoirs. The reliance of such projects on the weather can make the costs hard to justify.

Storm water may also be heavily polluted and is expensive to treat. This can make alternatives such as imposed water rationing or water transfers from other areas more attractive - despite their human and environmental costs. Stormwater treatment would be more economically viable if lesspurified water were used for nondrinking purposes. This would require wider public education, because the idea of recycled water is anathema to many.

For expanding cities, ways to deploy storm water will need to be embedded into urban planning. The technology is already available and could be tailored to different situations (see, for example, T. D. Fletcher et al. J. Environ. Qual.37, S-116S-127; 2008; A. E. Barbosa et al. Water Res. 46, 6787-6798; 2012). Shunsuke Managi Kyushu University, Fukuoka, Japan. Ashantha Goonetilleke, Clevo Wilson Queensland University of Technology, Brisbane, Australia. managi@doc.kyushu-u.ac.jp

\section{Engage engineers in soil management}

The UK government's Environmental Audit Committee is due to release a report on its enquiry into soil health by this summer. With most soil guidance for the United Kingdom coming from the European Union and the United Nations, the possibility of Britain leaving the EU ('Brexit') makes UK soil protection even more pressing.

US President Franklin D. Roosevelt declared in 1937 that "the nation that destroys its soils destroys itself" (see also L. Montanarella Nature 528, 32-33; 2015). Since agriculture became industrialized, we have been taking more organic matter out of soils than we put in. Together with urban development, flooding and only partial return of organic wastes to soil, this means that soil carbon is being depleted globally, not just in the United Kingdom.

Engineers could lead the way in redressing this balance, as they have for recycling precious metals such as catalytic platinum (see, for example, C. Hagelüken Platin. Met. Rev. 56, 29-35; 2012). For instance, they can stabilize carbon in organic wastes using minerals such as manganese oxides (K. Johnson et al. Nature Commun. 6, 7628 ; 2015) and optimize soil amendments to maintain and enhance soil ecosystem services. Engineers, who are currently largely excluded from sustainable soil management, will then be working with the environment — instead of just on top of it.

Karen L. Johnson Durham University, UK. karen.johnson@durham.ac.uk

\section{A global baseline for ecosystem recovery}

Indicators of success for ecosystem restoration depend on a proper assessment of the extent to which human activity has degraded biodiversity and ecosystem functions and services. In the run-up to the 13th Conference of the Parties on the 2020 Aichi biodiversity targets this year in Cancún, Mexico, we suggest how such assessments could be improved and standardized globally.

The current state of ecosystems is measured by using direct observations. To detect trends in degradation or recovery over time, we must also define a baseline reference state. However, an arbitrarily chosen baseline, such as 50 years ago, might not reflect the true magnitude or direction of land degradation or recovery.

Instead, we suggest using an ecosystem's pre-degradation state, also known as its natural state. This state has no humancaused loss of biodiversity or of ecosystem functions. Contrasted with the ecosystem's current state, it provides a robust indicator of damage or recovery. It is determined by scientific research, but should not be viewed as a restoration target those are merely political goals that balance social, economic and ecological interests.

A pre-degradation baseline could provide a universally applicable reference state. It reflects the deviation from genuine sustainability and, as a global standard, would ensure the fairness and comparability of ecosystem assessments across countries that are in different phases of economic development.

Janne S. Kotiaho University of Jyväskylä, Finland.

Ben ten Brink $P B L-N e t h e r l a n d s$ Environmental Assessment Agency, The Netherlands. Jim Harris Cranfield University, Bedfordshire, UK. janne.kotiaho@jyu.fi

\section{Holistic hydropower scheme for China}

We propose three ways in which China could cut the human and environmental cost of its hydropower developments.

First, reform the laws that govern new dam developments in China. These should include provisions to address the impact of individual projects on river basins. Measuring and understanding the cascade effects of dams and predicting ecosystem trends can guide decisions on fish propagation and optimal reservoir operation, for instance. Charges for hydroelectricity need to be rationalized and migrants' compensation standards updated. And inter-regional transfer payments to the authorities, intended to balance the social and environmental losses of affected areas with the gains in other areas, should correlate with the economic benefits of hydropower development.

Second, pay more attention to resettlement. Migrant populations could be relocated to mountainous areas along cascade reservoirs, which would boost infrastructure and preserve natural resources. People would need government help with land planning, education, employment and forming new social networks, without any devaluation of their indigenous knowledge, social capital or traditions.

Third, improve the governance of international rivers. China and its neighbours should share river management and water resources, cooperatively seeking solutions to the problems of hydropower production, environmental sustainability and climate change. China has a wealth of experience and technologies to contribute from its many previous hydropower projects. Wenzhe Tang ${ }^{\star}$ Tsinghua University, Beijing, China. twz@mail.tsinghua.edu.cn ${ }^{\star}$ On behalf of 7 correspondents (see go.nature.com/h6xza4 for full list).

\section{CORRECTION}

An article in the Nature Index 2016 Japan (Nature 531, S127-S130; 2016) wrongly described an alumina film as having high thermal conductivity; in fact, it has high thermal insulation. It also misnamed JEOL Ltd as JOEL. 